\title{
ECOLOGY AND BEHAVIOR
}

\section{Seasonal Occurrence of Henosepilachna vigintioctopunctata (F.) (Coleoptera: Coccinellidae) and Its Parasitoid on Ashwagandha in India}

\author{
M. G. Venkatesha* \\ Department of Studies in Zoology, Bangalore University, Jnana Bharathi Campus, Bangalore 560 056, Karnataka, India
}

\begin{abstract}
The outbreak of Henosepilachna vigintioctopunctata (F.) was noticed on a medicinal plant, Withania somnifera Dunal during 2004-05. The population level of the pest was reached its peak in August. The parasitoid Pediobius foveolatus caused $51.94 \% \pm 12.20 \%$ parasitism. The pest completed its life cycle in $20.15 \pm 1.50$ days on $W$. somnifera. The longevity of the male and female adults of the pest was $22.07 \pm 3.71$ and $31.07 \pm 4.38$ days, respectively. The gravid females of $H$. vigintioctopunctata laid an average of $287.64 \pm 33.38$ eggs during their oviposition period of $10.40 \pm 2.80$ days.
\end{abstract}

Key words Henosepilachna vigintioctopunctata, Withania somnifera, Pediobius foveolatus, incidence, parasitism

\section{Introduction}

The spotted leaf beetle, Henosepilachna vigintioctopunctata (F.) is an important pest of the solanaceous (e.g. brinjal, tobacco, tomato, potato, etc.) and cucurbitaceous (e.g. gourds, melon, cucumber, etc.) plants in India (Krishnamurti, 1932; Puttarudriah and Krishnamurti, 1954; Sengupta and Panda, 1959; Mandal, 1971; Mohansundaram and Uthamaswamy, 1973; Azam et. al., 1974). The pest also attacks wild species Amaranthus caudatus L. (Hameed and Adlakha, 1973) and some medicinal plants such as Physalis spp. (Mohansundaram and Uthamaswamy, 1973), Datura spp., Solanum spp. and Withania somnifera Dunal (Mathur and Srivastava, 1964). Henosepilachna vigintioctopunctata is widely distributed in Southeast Asian countries, Korea and Australia (Kapur, 1950). The pest has been noticed since many decades in

*Corresponding author.

E-mail: venkatmelally@gmail.com

Tel: +91-80-22961569; Fax: +91-80-23219295

(Received June 5, 2006; Accepted July 17, 2006) different parts of India (Krishnamurti, 1932; Jolly, 1962; Bassi, 1963). Rajagopal and Trivedi (1989) reviewed the status, bioecology and management of $H$. vigintioctopunctata. The high incidence of the pest has been reported during temperature range of 24$31^{\circ} \mathrm{C}$ and relative humidity $58-75 \% \mathrm{RH}$ in the field (Ramzan et. al., 1990; Ghosh and Senapati, 2001). The outbreak of $H$. vigintioctopunctata was noticed during 2004-2005 on $W$. somnifera plants in Bangalore, India. Withania somnifera is an important medicinal plant used in Ayurvedic formulations to treat various ailments of mankind (Sangwan et. al., 2004). To understand the status of the pest on ashwagandha, observations were made on the population level, biology and parasitization of $H$. vigintioctopunctata.

\section{Materials and Methods}

During the outbreak of the pest in the field in Bangalore city, the number of larvae and adults present on the third and fourth pairs of distal leaves from four middle branches from four cardinal sides of randomly selected four $W$. somnifera plants were recorded once a week. Prevailing climatic factors in the field during the study period were recorded daily. Six to ten medium sized larvae were collected randomly from four infested plants in the field once a week and reared them on fresh aswagandha leaves in the laboratory and parasitism per cent was recorded. To study the biology of $H$. vigintioctopunctata on $W$. somnifera in the laboratory, initially a few field-collected adults were reared in the glass jars $(12 \mathrm{~cm}$ diameter X 8 $\mathrm{cm}$ height) on fresh $W$. somnifera leaves and allowed to lay eggs. Newly emerged larvae in the laboratory were reared in Petri dishes $(10 \mathrm{~cm}$ diameter) and provided them fresh succulent aswagandha leaves daily until they reached pupal stage. The larvae were monitored regularly and moulting was confirmed by examining for exuviae and head capsules. The egg, 
larval and pupal developmental period, number of instars in a life cycle, longevity of adults were recorded during July. Sept. 2004 under ordinary laboratory conditions. The preoviposition and oviposition periods, and fecundity of female beetles were also documented. During insect rearing, daily temperature and relative humidity were recorded in the laboratory.

\section{Results and Discussion}

The outbreak of $H$. vigintioctopunctata on W. somnifera plants was found in the first week of July 2004 and 2005. The incidence of the pest population in relation to parasitism, temperature and relative humidity is given in Fig. 1. The adult and larval populations of the pest were found peak in mid August. However, decrease of the pest incidence was found in the last week of August reached to zero level in October. Similarly, the high level of $H$. vigintioctopunctata incidence on different crops was reported during June to October in various parts of India (Krishnamurti and Appanna, 1951; Mathur and Srivastava, 1964; Thakur, 1966; Hameed and Adlakha, 1973; Ramzan et. al. 1990; Ghosh and Senapati, 2001). During the peak period of the pest and its parasitoid the mean maximum temperature, minimum temperature and relative humidity was $27.56 \pm 0.88^{\circ} \mathrm{C}, 19.58 \pm 0.49^{\circ} \mathrm{C}$ and $75.55 \pm 13.37 \% \mathrm{RH}$, respectively. Ramzan et. al.(1990) and Ghosh and Senapati (2001) reported the peak incidence of $H$. vigintioctopunctata under similar climatic conditions. Irrespective of the availability of host plants throughout the year and favourable climatic factors, the pest population level was started to decrease from the last week of August onwards and reached to trace level in the first week of October perhaps due to high parasitic activities, which reached its peak along with the raising pest population in August.

Adults of Pediobius foveolatus (Crawford) (Hymenoptera: Eulophidae), a larval-pupal parasitoid were emerged from the field-collected $H$. vigintioctopunctata larvae that were reared in the laboratory. The per cent of $H$. vigintioctopunctata larvae parasitised by $P$. foveolatus during the incidence period of the pest is given in Fig. 1. The parasitoid caused 51.94 $12.20 \%$ parasitism in the field collected larvae of $H$. vigintioctopunctata. Pediobius foveolatus is known to be a potential parasitoid of various phytophagous coccinellids and caused up to $62 \%$ parasitism in Epilachna ocellata Redenbacher (Dhingra et. al., 1986 ) and $80 \%$ in E. philippinensis Dieke (Chiu and Moore, 1993). Natural parasitism of $H$. vigintiocto-

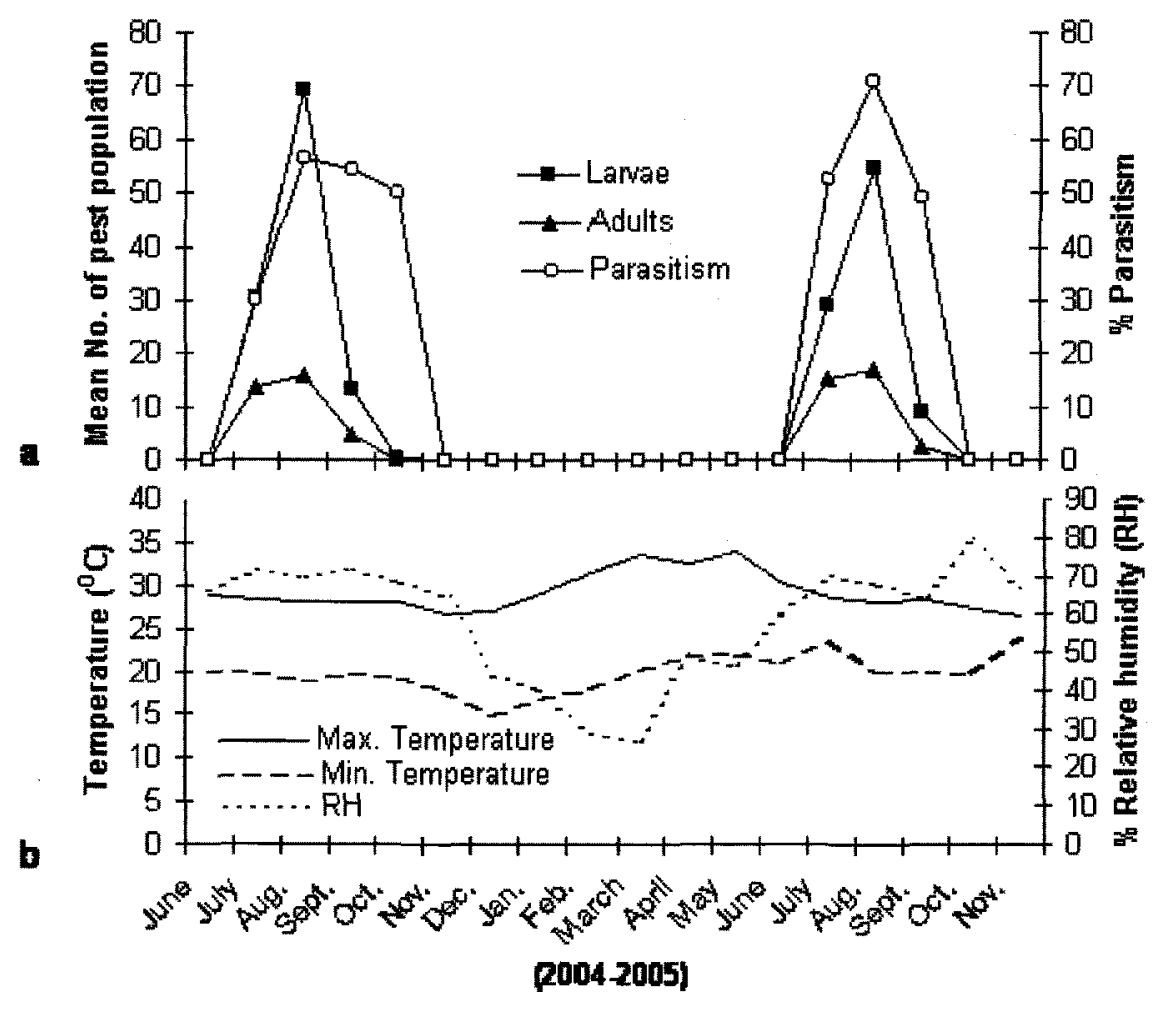

Fig. 1. a, Average monthly incidence of $H$. vigintioctopunctata and its parasitoid $P$. foveolatus on Withania somnifera in the field; b, Environmental variables during the pest incidence. 
punctata by $P$. foveolatus on eggplant was $47.1-49.5 \%$ (Rajendran and Gopalan, 1997), 28.47\% on potato and $64.5 \%$ on Solanum nigrum L. (Sheng and Wang, 1992). Puttarudriah and Krishnamurti (1954) reported about $60 \%$ parasitism of $H$. vigintioctopunctata grubs on potato and suggested that insecticide application is not required as parasite activity alone keeps the pest population below economic threshold in the field. Similar condition was noticed in the case of $W$. somnifera infestation.

The pest deposited the eggs in clusters on the lower surface of the leaves. There were four larval stages as reported earlier (Krishnamurti, 1932; Kapur, 1950; Gupta and Kumar, 1984). First instar larvae fed gregariously and they became non-gregarious form second instar onwards. Kapur (1950) studied the larval morphology of $H$. vigintioctopunctata. The larvae scraped epidermal layer of the leaves and sometimes skeletonized the entire leaf. The developmental period of the egg, larval instars, prepupa and pupa is given in Table 1.

The adult beetles started feeding a day after emergence. The adults also fed on epidermal layer of the leaves as larvae do, but sometimes made tattered holes on the leaves in the field. Newly emerged adults died within 2-3 days without food. The adults first mated in 2-3 days after emergence. Individual pair copulated several times and a single copulation lasted for 1-3 minutes. The preoviposition period was $6.00 \pm 1.56$ days. The gravid females laid $287.64 \pm 33.38$ eggs in 4-6 batches during their oviposition period of $10.40 \pm$
2.80 days. The highest number of eggs was deposited on the first day of oviposition and it was gradually decreased in subsequent depositions (Table 2). The longevity of the male and female beetles was $22.07 \pm$ 3.71 and $31.07 \pm 4.38$ days, respectively. The pest completed its life cycle in $20.15 \pm 1.50$ days under the variable maximum temperature $28.33 \pm 1.80^{\circ} \mathrm{C}$, minimum temperature $19.77 \pm 0.68^{\circ} \mathrm{C}$ and relative humidity $72.03 \pm 13.09 \%$. Henosepilachna vigintioctopunctata has been known to complete its life cycle in 22-30 days depending upon the species of host plants on which it feeds and prevailing climatic conditions such as temperature and relative humidity (Chowdhuri, 1965; Ramzan et. al., 1990; Ghosh and Senapati, 2001). Although several workers (Jayakumari and Nair, 1969; Hameed and Adlakha, 1973; Peter and Govindarajalu, 1989; Rao et. al., 1989; Thomas and Jacob, 1991; Umapathy and Baskaran, 1991; Mala et. al., 1992; Rao et. al., 1992; Prasad and Logiswaran, 1993; Gupta and Dogra, 1994; Reddy, 1997) suggested different insecticides for the control of $H$. vigintioctopunctata, chemical control measures may not be required because of high level of larval parasitization of the pest on ashwagandha similar to that recorded on other host plants (Puttarudriah and Krishnamurti, 1954; Sheng and Wang, 1992; Rajendran and Gopalan, 1997). Even though $P$. foveolatus parasitizes all larval stages of $H$. vigintioctopunctata, it prefers later instars (Sheng and Wang, 1992). Therefore, it is always essential to retain fully-grown larvae of the pest in the field for parasitic activities to exert maxi-

Table 1. Developmental period (days) of different stages of $H$. vigintioctopunctata on $W$. somnifera under the ordinary laboratory conditions.

\begin{tabular}{cccc}
\hline \multicolumn{2}{c}{ Stage } & No. of samples & Duration of development Mean \pm SD \\
\hline Egg & & 20 & $3.79 \pm 0.49$ \\
Larva: & & 20 & \\
I & Instar & 20 & $2.50 \pm 0.55$ \\
II & Instar & 20 & $2.52 \pm 0.54$ \\
III & Instar & 20 & $2.50 \pm 0.52$ \\
IV & Instar & 20 & $3.58 \pm 0.54$ \\
Prepupa & 20 & $1.06 \pm 0.08$ \\
Pupa & 20 & $3.75 \pm 0.56$ \\
\hline
\end{tabular}

Table 2. Egg laying trend of $H$. vigintioctopunctata reared on $W$. somnifera under the ordinary laboratory conditions.

\begin{tabular}{ccc}
\hline Days of oviposition & Batch No. of egg cluster & Number of eggs deposited* Mean \pm SD \\
\hline 1 & I & $90.89 \pm 12.87$ \\
$2-3$ & II & $78.56 \pm 12.49$ \\
$4-6$ & III & $60.67 \pm 15.82$ \\
$7-9$ & IV & $36.22 \pm 10.12$ \\
$10-13$ & V & $23.44 \pm 6.80$ \\
$14-16$ & VI & $17.25 \pm 5.25$ \\
\hline
\end{tabular}

*Mean of 10 gravid females 
mum natural control that keeps the pest below economic threshold level without the application of any harmful pesticides on the valuable medicinal plant. To avoid the damage caused by early larval stages of $H$. vigintioctopunctata as $P$. foveolatus prefers fourth instar larvae for parasitization, hand picking and destruction of the adults, larval stages and egg masses of the pest in the field could be useful to control the pest population effectively as suggested for Epilachna beetles of brinjal (Ayyar, 1984).

Acknowledgement The author thanks Dr. J. Poorani (Project Directorate of Biological Control, Hebbal, Bangalore 560024, Karnataka, India) for identification of the pest and parasitoid.

\section{Literature Cited}

Ayyar, T. V. R. 1984. Hand of book of economic entomology for South India. 528pp. International Books \& Periodicals Supply Service, New Delhi.

Azam, K. M., S. A. Aziz and M. H. Ali. 1974. A new record of Uga menoni as parasite of Epilachna vigintioctopunctata in India. Curr. Res. 3: 88

Bassi, K. K. 1963. Record of Epilachna vigintioctopunctata Fab. in Simla hills. Indian Potato J. 5: 105-106.

Chiu, C. H. and A. Moore. 1993. Biological control of the Philippine lady beetle, Epilachna philippinensis (Coleoptera: Coccinellidae), on solanaceous plants by the parasitoid, Pediobius foveolatus (Hymenoptera: Eulophidae), on Saipan. pp. 79-80, In Proceedings XIX International Cong. Entomol. 4 suppl.

Chowdhuri, A. N. 1965. Control of Epilachna beetles attacking potato in Simla hills. Indian Potato J. 7: 108.

Dhingra, M. R., S. V. Dhamdhere and R. R. Rawat. 1986. Natural enemies of Epilachna ocellata Redenbacher at Jabalpur (Madhya Pradesh). Bull. Entomol. 27: 184-185.

Ghosh, S. K. and S. K. Senapati. 2001. Biology and seasonal fluctuation of Henosepilachna vigintioctopunctata Fabr. on brinjal under Terai region of West Bengal. Indian J. Agric. Res. 35: 149-154.

Gupta, J. K. and A. Kumar. 1984. Effect of gamma radiation on solanaceous Hadda, E. vigintioctopunctata: radiosensitivity of different stages. Indian J. Entomol. 4: 467-475.

Gupta, P. R. and G. S. Dogra. 1994. Sensitivity of stages of development of Henosepilachna vigintioctopunctata (Fab.) to topical application of diflubenzuron and penfluron. J. Insect Sci.7: 143-147.

Hameed, S. F. and R. L. Adlakha. 1973. Studies on the population and control of Epilachna species on potato in Kulu Valley. Pesticides 7: 30-31.

Jayakumari, R. and M. R. G. K. Nair. 1969. Susceptibility of larval stages of $E$, vigintioctopunctata to insecticides. Agric. Res. Kerala 6: 105-107.

Jolly, C. L. 1962. Biology and bionomics of E. ocellata. Indian Potato J. 4: 17-21.

Kapur, A. P. 1950. Biology and external morphology of larvae of Epilachininae (Coleoptera: Coccinellidae). Bull. Entomol. Res. 41: 161-208.

Krishnamurti, B. and M. Appanna. 1951. Occurrence, distribution and control of major insect pests of some important crops in Mysore. Mysore Agric. J. 27: 1-23.

Krishnamurti, B. 1932. The potato epilachna beetle, E. vigintioctopunctata. Bull. Dept. Agric., Mysore (Entomol. Ser.),
9: $1-16$.

Mala, S. R., C. Peter and B. V. David. 1992. Activity of certain insecticides on eggs of the spotted leaf beetle, Henosepilachna vigintioctopunctata $\mathrm{F}$. on brinjal. Indian J. Plant Protec. 20: 95-98.

Mandal, S. C. 1971. A note on the host range of Epilachna beetle, E. vigintioctopunctata in Bihar. Allahabad Farmer 45: $187-188$

Mathur, A. C. and J. B. Srivastava. 1964. E. vigintioctopunctata as a defoliator of some solanaceous medicinal plants. Indian J. Entomol. 26: 246.

Mohansundaram, M. and S. Uthamaswamy. 1973. A note on the Epilachna spp. commonly found in Tamil Nadu with observation on the host range and distribution. Sci. culture 39: 305-306

Peter, C. and V. Govindarajalu. 1989. Persistent toxicity of some insecticides to the spotted leaf beetle on brinjal. Curr. Res. Uni. Agric. Sci. Bangalore 18: 21-23.

Prasad, G. S. and G. Logiswaran. 1993. Toxicity of some chemicals to the grubs of brinjal spotted-beetle. J. Andaman Sci. Aso. 9: 77-78.

Puttarudriah, M. and B. Krishnamurti. 1954. Problem of Epilachna control in Mysore. Insecticidal control found inadvisable when natural incidence of parasites is high. Indian J. Entomol. 16: 137-141.

Rajagopal, D. and T. P. Trivedi. 1989. Status, bioecology and management of Epilachna beetle, Epilachna vigintioctopunctata (Fab.) (Coleoptera: Coccinellidae) on potato in India: a review. Trop. Pest Manage. 35: 410-413.

Rajendran, B. and M. Gopalan. 1997. Pediobius foveolatus Craw (Eulophidae: Hymenoptera) a potential parasitoid on the grubs of eggplant spotted beetle Henosepilachna vigintioctopunctata Fab. Entomon, 22: 147-149.

Ramzan, M., D. Singh, G. Singh, G. S. Mann and J. S. Bhalla 1990. Comparative development and seasonal abundance of Hadda beetle, Henosepilachna vigintioctopunctata (Fabr.) on some solanaceous host plants. J. Res. Punjab Agric. Uni. 27: 253-262.

Rao, P. K., K. V. S. Reddy and K. C. Chitra. 1992. Comparative efficacy of chitin synthesis inhibitors diflubenzuron and penfluron on Henosepilachna vigintioctopunctata (Fab.). J. Insect Sci. 5: 159-160.

Rao, V. R., K.C. Chitra and P. K. Rao. 1989. Relative toxicity of synthetic pyrethroids to Henosepilachna vigintioctopunctata (Fabricius). Indian J. Entomol. 51: 51-54.

Reddy, A. V. 1997. Evaluation of certain new insecticides against the foliar insect pests of bittergourd (Momordica charantia Linn). Ann. Agric. Res. 18: 255-257.

Sangwan, R. S., N. D. Chaurasiya, L. N. Misra, P. Lal, G. C. Uniyal, R. Sharma, N. S. Sangwan, K. A. Suri, G. N. Qazi and R. Tuli 2004. Phytochemical variability in commercial products and preparations of Withania somnifera (Ashwagandha). Curr. Sci. 86: 461-465.

Sengupta, G. C. and N. Panda. 1959. Insecticidal control of Epilachna vigintioctopunctata (F.). J. Econ. Entomol. 51: 749.

Sheng, J. K. and G. H. Wang. 1992. Studies on the biology of Pediobius foveolatus (Hym.: Pteromalidae) in the Nanchang area. Chinese J. Biol. Control, 8: 110-114.

Thakur, M. R. 1966. Common insect pests of temperate vegetable crops with special reference to Upper Kulu Valley. Punjab Hortic. J. 6: 188-192.

Thomas, C. and S. Jacob.1991. Bio-efficiency of carbofuran against the epilachna beetle, Henosepilachna 28 punctata Fab. infesting bittergourd (Momordica charantia L.) under field and laboratory conditions. Indian J. Entomol. 53: 435-441.

Umapathy, G. and P. Baskaran. 1991. Bioefficacy of certain synthetic pyrethroids against major pests of brinjal. Madras Agric. J. 78: 8-10. 